Research Paper

\title{
Cetuximab in Reiractory Skin Cancer Treatment
}

\author{
Sini J Kalapurakal1, James Malone ${ }^{4,6}$, K. Thomas Robbins4,6, Lucinda Buescher ${ }^{5}$, John Godwinn, ${ }^{2,6}$, Krishna \\ $\mathrm{RaO}^{2,3,6}$ 网
}

1. Department of Internal Medicine

2. Division of Hematology/Oncology, Department of Internal Medicine

3. Department of Medical Microbiology

4. Division of Otolaryngology Head and Neck Surgery, Department of Surgery,

5. Division of Dermatology, Department of Internal Medicine, Southern Illinois University School of Medicine;

6. Simmons Cancer Institute at SIU, Springfield, IL.

Corresponding author: Krishna A. Rao, M.D., Ph.D., Associate Professor of Medicine, Division of Hematology and Oncology, Department of Internal Medicine, Southern Illinois University School of Medicine, Post Office Box 19678, Springfield, IL 62794-9678, Phone: 217-545-7045, Fax: 217-545-7021 Email: krao@siumed.edu

(C) Ivyspring International Publisher. This is an open-access article distributed under the terms of the Creative Commons License (http:/ / creativecommons.org/ licenses/by-nc-nd/3.0/). Reproduction is permitted for personal, noncommercial use, provided that the article is in whole, unmodified, and properly cited.

Received: 2011.09.08; Accepted: 2012.05.28; Published: 2012.06.07

\begin{abstract}
Objectives: Non-melanoma skin cancer is the most common malignancy in US, with an annual incidence of in excess of 1.5 million cases. In the majority of cases, locoregional treatment is curative and systemic therapy is not indicated. Platinum-based chemotherapy regimens have been used most commonly in refractory cases. The use of cetuximab, a monoclonal antibody targeting epidermal growth factor receptor [EGFR], has been reported for skin cancer treatment. This current study evaluated eight cases of locally advanced and refractory basal cell or squamous cell cancers which were treated with cetuximab.

Methods: This is a retrospective study on eight patients who had received cetuximab for treatment of cutaneous carcinoma since 2007 at Southern Illinois University School of Medicine (SIU-SOM) Medical Oncology clinic.

Results: Three of the four patients with basal cell carcinoma and two of the four patients with squamous cell carcinoma maintained remission on treatment.. The main side effect was acneiform rash which required termination of treatment for one patient and dose reduction in another.

Conclusion: The study indicates that cetuximab may have a beneficial role for patients with non-melanoma cutaneous carcinomas that are refractory to standard therapy.
\end{abstract}

Key words: cetuximab, non-melanoma, skin cancer

\section{Introduction}

As per the United Nations Environment Programme (UNEP), global incidence of non-melanoma skin cancer exceeds 2 million each year [2]. With a $10 \%$ decrease in stratospheric ozone, this number is being expected to increase by 300,000 annually [2]. Seventy-five percent of the non-melanoma skin cancers are basal cell carcinomas (BCC), which are usu- ally effectively treated with excision. The remaining are predominantly squamous cell carcinomas (SCC). Treatment options for SCC vary depending on the severity of the disease, but surgical excision alone is generally adequate treatment. However, for high risk SCC patients, which include those with inadequately excised and recurrent lesions, lymph node metastasis, 
and immunosuppression, the current treatment recommendation is combined surgery and radiation [3]. Patients with high risk cutaneous SCC includes those with inadequately excised and recurrent lesions, lymph node metastasis, and immunosuppression [3]. At the molecular level, over expression of EGFR is considered a predictive factor for identification of high-risk SCC [3]. The combination of radiation treatment and surgery has reduced the rate of locoregional relapse by $20-25 \%$ [4]. As per Porceddu et al, patients with high-risk pathologic features such as multiple nodes, extra nodal spread, positive margins, and perineural and vascular invasion will benefit from concurrent platinum-based chemotherapy and radiation treatment [5]. Platinum-based chemotherapy regimens have been used most commonly in refractory cases. But, this is frequently a patient population with advanced age and multiple co-morbidities, in which platinum-based regimens are least tolerated. Systemic therapy is recommended only in patients with refractory disease.

Cetuximab is a chimeric human/murine monoclonal antibody that binds competitively to EGFR and prevents activation of the receptor [6]. Considering the low side effect profile, interest in cetuximab as a treatment for non-melanoma skin cancer is growing area. Compared to currently approved chemotherapies for skin carcinomas, it is well tolerated. Most adverse skin reactions expected with this treatment are cutaneous and include acneiform eruption, xerosis, paronychia, hair changes, telangectasia and hyperpigmentation. The most common adverse effect is acneiform rash which is seen in $50-100 \%$ of patients [7]. This is assumed to be due to interference with the physiological role of EGFR in the epidermis. There are reported cases of severe acneiform rash, mucositis and dermatitis in people treated with combined radiation and cetuximab [8;9]. There is also one reported case of toxic epidermal necrolysis caused by cetuximab plus minocycline in a patient receiving chemoradiation for recurrent squamous cell carcinoma of head and neck which evolved in the 5th week of treatment with cetuximab [10].

Here, we evaluate eight cases of advanced squamous cell carcinoma or basal cell carcinoma patients treated with cetuximab. Among the eight patients, four were basal cell carcinoma and four were squamous cell carcinoma.

\section{Patients and Methods}

A retrospective analysis was performed using the records of the SIU-S between the years 2007-2011. Local institutional board approval (exempt approval on $01 / 21 / 2010$ ) was obtained before the beginning of the study. Eight patients were identified who had received cetuximab for treatment of skin carcinoma. Collected from the case records were demographic data including age, co-morbidities, and family history. Tumor characteristics included histology, stage and treatment factors included previous interventions, dose and frequency of cetuximab, and adverse effects of cetuximab. Assessment of disease status was based on physical examination documented in the clinic notes and imaging studies. Complete and partial remission (CR \& PR) has been determined based on RECIST criteria except the fact that patients may or may not been continuing the treatment during that time [11]. The follow-up period started from the date that treatment was initiated.

\section{Results}

Among the eight patients analyzed, four had basal cell carcinoma and four had squamous cell carcinoma. The median age of the patient cohort is 79 (Table 1).

Table I: Patient characteristics.

\begin{tabular}{|c|c|c|c|}
\hline Characteristics & All patients & $\begin{array}{l}\text { Basal cell } \\
\text { carcinoma }\end{array}$ & $\begin{array}{l}\text { Squamous } \\
\text { cell carcinoma }\end{array}$ \\
\hline Number of patients & 8 & 4 & 4 \\
\hline Median age & $79(38-89)$ & $84(45-87)$ & $71.5(38-89)$ \\
\hline $\begin{array}{l}\text { History of Gorlin syn- } \\
\text { drome }\end{array}$ & 3 & 3 & 0 \\
\hline $\begin{array}{l}\text { Family history of skin } \\
\text { cancer }\end{array}$ & 3 & 3 & 0 \\
\hline $\begin{array}{l}\text { History of immunosup- } \\
\text { pressant use }\end{array}$ & 2 & 0 & 2 \\
\hline
\end{tabular}

Three of the four patients with BCC had Gorlin syndrome with a significant family history of basal cell carcinoma. The age group of these patients varied from 45-87, including three above the age of 80 . All of the octogenarians had multiple medical problems and required multiple surgeries and excisions of basal cell carcinomas that had resulted in deformities in the head and neck area. Except for one SCC patient who had received Carboplatin and Docetaxel chemotherapy, none of the other seven patients received any prior chemotherapy. The fourth BCC patient, without a history of Gorlin Syndrome, had an aggressive basal cell carcinoma that warranted numerous resections over several years as well as radiation therapy. He ultimately developed regional lymph node metastasis and was referred for further management of his pro- 
gressive disease that was considered refractory to any further radiation or surgery.

Four patients, aged 38 to 89 , had recurrent squamous cell carcinoma with a history of multiple recurrences in the past. Two patients had lymph node metastasis. Two patients had a history of renal transplantation and concomitant immunosuppression. One was on Mycophenolate and presented with a right temple lesion that recurred four times. It was treated initially with surgery and combined cetuximab and radiation for the second recurrence. The third and fourth recurrences were also treated with surgery. The other patient presented with a metastatic squamous cell carcinoma of unknown primary with mediastinal adenopathy, neck mass and pulmonary nodules. He failed Carboplatin/ Docetaxel chemotherapy and developed progressive disease with a pericardial effusion, necessitating a pericardial window. He was placed on cetuximab with complete clearing of his lesions. He ultimately lost his transplanted kidney due to infection. His transplanted kidney was surgically removed, and all of his immunosuppression was stopped.

For five out of the 8 patients, the starting dose of cetuximab was $125 \mathrm{mg} / \mathrm{m}^{2}$ once a week. One of the patients with BCC received cetuximab $250 \mathrm{mg} / \mathrm{m}^{2}$ once a week, and the latter dose was subsequently escalated to $300 \mathrm{mg} / \mathrm{m}^{2}$. The starting dose of cetuximab for 2 of the BCC patients was $125 \mathrm{mg} / \mathrm{m}^{2}$ once a month. The dose was gradually increased up to 250 $\mathrm{mg} / \mathrm{m}^{2}$ for one of the patients. One of the SCC patients started with cetuximab $250 \mathrm{mg} / \mathrm{m} 2$ once a week for eight weeks as induction treatment. The same patient continued maintenance treatment for two and half years as cycles of once a week treatment for four weeks with two weeks off.

The adverse reactions observed during therapy are outlined in Table 2. Five out of 8 patients $(63 \%)$ experienced grade II acneiform skin rash as a side effect, which was usually noted after 2-3 treatments. One patient was treated with steroids and minocycline because the rash recurred after each treatment. Another patient required premature termination of cetuximab due to persistent skin rash despite treatment with steroids and minocycline. This latter patient was subsequently able to tolerate cetuximab with a $50 \%$ dose reduction when it was restarted for disease recurrence. For the remaining three patients, the grade II skin rash resolved with 2-3 weeks of minocycline treatment. One patient experienced grade II fissuring of the skin and improved with topical medications. This patient later developed grade II skin induration and grade III skin pain after two and half years of treatment and stopped therapy. Skin biopsy later proved nephrogenic systemic sclerosis. Grade I hypomagnesaemia was observed in two patients. They were treated with magnesium intravenously (IV) with each treatment.

Among the four patients with BCC, fifty percent attained complete remission (CR) and 50\% attained partial remission (PR) with treatment. Three patients relapsed after stopping the treatment (2 CR and $1 \mathrm{PR})$ and currently have been placed back on cetuximab. One patient remains on maintenance treatment for the last 12 months after attaining an initial partial response. Another patient had a local recurrence of the disease after a four-month hiatus from treatment and now remains on maintenance treatment. The third BCC patient had two recurrences after the first treatment with cetuximab, which had to be discontinued after four cycles secondary to skin rash. However, disease remission had been attained by that time. The first recurrence occurred two months after discontinuing cetuximab but responded to reinstitution of treatment for seven months. The second recurrence occurred after five months off therapy, but remission was obtained again with the reinitiation of cetuximab, and the patient has been on maintenance treatment for the last seven months. The fourth patient, who had a partial response with cetuximab, had a multifocal recurrence soon after being off treatment. He was then started on a multidrug chemotherapy regimen with 5-Flurouracil, carboplatin, and cetuximab. He achieved a near complete response to three cycles of chemotherapy but therapy was stopped due to his advanced age and performance status. His disease recurred several months later, and he chose to receive supportive care only at that point. The median follow-up for the BCC patients is 12 months. Median disease-free survival was 1 month. With a median follow up of 12 months, overall survival was $100 \%$. Median survival is not yet reached (Table 3).

Three of the four patients with SCC obtained a CR. One relapsed at 6 months following active treatment, and the other two have been in remission for the past 3 years. The latter two patients had a renal transplant and had previously been on Mycophenolate or other immunosuppression. The patients had been off the immunosuppressant for the past 3 years. The patient who had a partial response died secondary to other co-morbidities before any further follow-up. Median follow-up and disease- free survival were 32.5 months and 20.5 months, respectively. Over the 30 months follow up period, the overall survival was $75 \%$. Median survival has not been reached (Table 3). 
Table 2: Adverse effects.

\begin{tabular}{lllll}
\hline Side effects & Grade 1 & Grade 2 & Grade 3 \& 4 & Total Number \\
\hline Skin rash* & $3 / 8(37.5 \%)$ & $2 / 8(25 \%)$ & 0 & $5(62.5 \%)$ \\
Hypomagnesemia* & $2 / 8(25 \%)$ & 0 & 0 & $2 / 8(25 \%)$ \\
Skin fissuring* & 0 & $1 / 8(12.5 \%)$ & 0 & $1 / 8(12.5 \%)$
\end{tabular}

* number of patients.

Table 3: Follow up data.

\begin{tabular}{llll}
\hline Parameters & All patients & Basal cell carcinoma & Squamous cell carcinoma \\
\hline Median follow up & 17 months & 12 months & 32.5 months \\
Complete remission* & $5 / 8(62.5 \%)$ & $2 / 4(50 \%)$ & $3 / 4(75 \%)$ \\
Partial remission* & $3 / 8(37.5 \%)$ & $2 / 4(50 \%)$ & $1 / 4(25 \%)$ \\
Relapse* & $5 / 8(62.5 \%)$ & $3 / 4(75 \%)$ & $2 / 4(50 \%)$ \\
Median disease free survival & 4 months & 1 month & 20.5 months \\
Median overall survival & Not reached & Not reached & Not reached \\
\hline
\end{tabular}

* number of patients.

\section{Discussions}

This study shows that recurrent non-melanoma skin cancers can be successfully treated with extended cetuximab therapy. 62.5 percent of the study patients obtained a complete remission and a major response (CR and PR) was achieved in all of the patients. However, among those whose treatment was held, $63 \%$ of the patients subsequently relapsed. For the three patients who had a sustained remission, two have continued the maintenance treatment, and the other one has stopped. Our median disease-free survival was only 4 months. Over the 17 months median follow up period, the overall survival is $88 \%$. The median overall survival has not yet been reached. Among the total group, $63 \%$ and $25 \%$ of patients had grade II skin rash and grade 1 hypomagnesemia, respectively. $13 \%$ of the patients experienced grade II fissuring. The skin induration and skin pain experienced by one patient were considered to be unrelated adverse events. No other adverse events were noted, and no one developed grade III or IV toxicities with treatment.

Epidermal growth factor receptor [EGFR] is a member of tyrosine kinase growth factor receptor family. Activation of this receptor results in intracellular tyrosine kinase autophosphorylation, which initiates a cascade of intracellular events ultimately leading to cell cycle progression, angiogenesis, metastasis and reduced apoptosis [12]. EGFR is normally expressed in human cells, but higher levels of expression have been shown in many malignancies. As per
Krahn, $80 \%$ of SCC and $57 \%$ of BCC express EGFR [13]. As per previous studies, aberration in EGFR pathways is associated with poor prognosis in many malignancies. Even though BCC also expresses EGFR, the key pathology in BCC is an aberration in the hedgehog pathway $[14 ; 15]$. Novel inhibitors of this pathway such as GDC-0449 are on trial but are not yet clinically approved [16]. It has been shown that EGFR signaling acts synergistically with the hedgehog pathway in the malignant transformation of cells $[17 ; 18]$. This may explain the effectiveness of cetuximab in patients with BCC.

We were able to obtain either a CR or a PR for all of our patients. However, we had a significant relapse rate for patients when treatment was stopped, which emphasizes the importance of maintenance treatment for long-term disease control. Even though median disease free survival was only one month, overall survival over the 30 month follow up period was $75 \%$. All of these patients had refractory disease, and we were able to prolong their life with a relatively low toxicity treatment regimen.

Compared to currently approved chemotherapies for skin carcinomas, cetuximab is well tolerated. In our study, the most commonly experienced side effect was acneiform skin rash occurring in 63\% of patents, which is consistent with a prior study [7]. All of skin rashes were grade II in severity, which were treated successfully with steroids and minocycline. Concurrent radiation treatment increases the incidence of serious adverse events as per the case reports that we discussed earlier. Only one of our patients 
had received radiation treatment along with cetuximab treatment, and he subsequently responded to single agent cetuximab therapy along with immunosuppressant modulation.

There have been isolated case reports of using cetuximab in recurrent non-melanoma skin cancers with favorable responses [19-22]. However, there have been no studies comparing efficacy of treatment with cetuximab versus currently approved chemotherapeutic agents for cutaneous malignancies. The results of the above reported cases are encouraging for the use of cetuximab in refractory non-melanoma skin cancers and suggest that a randomized phase III study between chemotherapy and cetuximab in this condition may be useful.

\section{Competing Interests}

The authors have declared that no competing interest exists.

\section{References}

1. Urba W, Washington C, Nadiminti H. Cancer of the Skin Chapter 87. In: Longo DL, Fauci AS, Kasper DL, Hauser SL, Jameson JL, Loscalzo J, eds. Harrison's Principles of Internal Medicine; 18th ed. 2012.

2. [Internet] Geneva, Switzerland: World Health Organization. Too Much Fun in the Sun Dangerous; Press Release WHO/40; 3 August 1999. http://www.who.int/inf-pr-1999/en/pr99-40.html

3. Veness MJ. Treatment recommendations in patients diagnosed with high-risk cutaneous squamous cell carcinoma. Australas Radiol 2005; 49(5):365-376.

4. Veness MJ, Porceddu S, Palme CE, Morgan GJ. Cutaneous head and neck squamous cell carcinoma metastatic to parotid and cervical lymph nodes. Head Neck 2007; 29(7):621-631.

5. Porceddu S, Campbell B, Rischin D, Corry J, Weih L, Guerrieri M et al. Postoperative chemoradiotherapy for high-risk head-and-neck squamous cell carcinoma. Int J Radiat Oncol Biol Phys 2004; 60(2):365-373

6. Harding J, Burtness B. Cetuximab: an epidermal growth factor receptor chemeric human-murine monoclonal antibody. Drugs Today (Barc ) 2005; 41(2):107-127.

7. Segaert S, Van CE. Clinical signs, pathophysiology and management of skin toxicity during therapy with epidermal growth factor receptor inhibitors. Ann Oncol 2005; 16(9):1425-1433.

8. Tejwani A, Wu S, Jia Y, Agulnik M, Millender L, Lacouture ME. Increased risk of high-grade dermatologic toxicities with radiation plus epidermal growth factor receptor inhibitor therapy. Cancer 2009; 115(6):1286-1299.

9. Koutcher LD, Wolden S, Lee N. Severe Radiation Dermatitis in Patients With Locally Advanced Head and Neck Cancer Treated With Concurrent Radiation and Cetuximab. Am J Clin Oncol 2009 Oct;32(5):472-6.

10. Lee SS, Chu PY. Toxic epidermal necrolysis caused by cetuximab plus minocycline in head and neck cancer. Am J Otolaryngol 2010; 31(4):288-290.

11. Eisenhauer E, Therasse P, Bogaerts J, Schwartz L, Sargent D, Ford R et al. New response evaluation criteria in solid tumours:revised RECIST guideline (version1.1). Eur J Cancer. 2009 Jan;45(2):228-47.

12. Castillo L, Etienne-Grimaldi MC, Fischel JL, Formento P, Magne N, Milano G. Pharmacological background of EGFR targeting. Ann Oncol 2004; 15(7):1007-1012.

13. Krahn G, Leiter U, Kaskel P, Udart M, Utikal J, Bezold G et al. Coexpression patterns of EGFR, HER2, HER3 and HER4 in non-melanoma skin cancer. Eur J Cancer 2001; 37(2):251-259.

14. Booth DR. The hedgehog signalling pathway and its role in basal cell carcinoma. Cancer Metastasis Rev 1999; 18(2):261-284.

15. Epstein EH. Basal cell carcinomas: attack of the hedgehog. Nat Rev Cancer 2008; 8(10):743-754.
16. Low JA, de Sauvage FJ. Clinical experience with Hedgehog pathway inhibitors. J Clin Oncol 2010; 28(36):5321-5326.

17. Schnidar H, Eberl M, Klingler S, Mangelberger D, Kasper M, Hauser-Kronberger $\mathrm{C}$ et al. Epidermal growth factor receptor signaling synergizes with Hedgehog/GLI in oncogenic transformation via activation of the MEK/ERK/JUN pathway. Cancer Res 2009; 69(4):1284-1292.

18. Mimeault M, Batra SK. Frequent deregulations in the hedgehog signaling network and cross-talks with the epidermal growth factor receptor pathway involved in cancer progression and targeted therapies. Pharmacol Rev 2010; 62(3):497-524.

19. Bauman JE, Eaton KD, Martins RG. Treatment of recurrent squamous cell carcinoma of the skin with cetuximab. Arch Dermatol 2007; 143(7):889-892.

20. Jalili A, Pinc A, Pieczkowski F, Karlhofer FM, Stingl G, Wagner SN. Combination of an EGFR blocker and a COX-2 inhibitor for the treatment of advanced cutaneous squamous cell carcinoma. J Dtsch Dermatol Ges 2008; 6(12):1066-1069.

21. Arnold AW, Bruckner-Tuderman L, Zuger C, Itin PH. Cetuximab therapy of metastasizing cutaneous squamous cell carcinoma in a patient with severe recessive dystrophic epidermolysis bullosa. Dermatology 2009; 219(1):80-83.

22. Suen JK, Bressler L, Shord SS, Warso M, Villano JL. Cutaneous squamous cell carcinoma responding serially to single-agent cetuximab. Anticancer Drugs 2007; 18(7):827-829. 